\title{
La intervención de riesgo, vía para revitalizar el patrimonio construido. Entrevista con Felipe Leal
}

\author{
Juan Ignacio del Cueto Ruiz-Funes
}

P rofesor y exdirector de la Facultad de Arquitectura de la Universidad Nacional Autónoma de México (UNAM), Felipe Leal Fernández (México, D.F., 1956) fue coordinador de Proyectos Especiales de la UNAM (20052008), antes de ser nombrado Autoridad del Espacio Público de la Ciudad de México, figura creada para proponer, normar y coordinar los trabajos encaminados a recuperar y mejorar el espacio público en la capital. Desde 2009, es secretario de Desarrollo Urbano y Vivienda (Seduvi) del Gobierno del Distrito Federal. A lo largo de su carrera como profesional independiente y como servidor público ha tenido oportunidad de intervenir a diferentes escalas, desde la doméstica hasta la urbana, sobre patrimonio construido.

Entre sus trabajos particulares en el campo de la intervención arquitectónica destacan las remodelaciones de casas habitación para intelectuales y artistas de la talla de Gabriel García Márquez, Alejandro Rossi, Juan Villoro, y Alejandro Aura y Carmen Boullosa, así como adecuaciones para establecimientos comerciales o culturales, como El Hijo del Cuervo en Coyoacán, la Casa Refugio Citlaltépetl en la colonia Condesa y las oficinas para la revista Artes de México en la colonia Roma. Sus trabajos en el ámbito público van desde las intervenciones que realizó en la Facultad de Arquitectura cuando fue su director (1997-2005), hasta las más recientes en zonas emblemáticas de la ciudad, como la calle Madero en el Centro Histórico y la Plaza de la República.

Felipe Leal complementa sus actividades con la difusión de la cultura arquitectónica a través de su programa "En el Espacio y en el Tiempo", que lleva más de 15 años de transmisión ininterrumpida por Radio UNAM. Esta entrevista, en la que desgrana algunas de sus reflexiones sobre la preservación y la revitalización de nuestro patrimonio construido, tuvo lugar el 25 de octubre de 2011 en la librería Rosario Castellanos del Fondo de Cultura Económica, que forma parte del Centro Cultural Bella Época, buen ejemplo de lo que él llama intervenciones de riesgo, en este caso, por la reforma radical que el arquitecto Teodoro González de León realizó en lo que fuera el cine Lido, rebautizado más tarde como Bella Época, en la colonia Condesa. 
JUAN IGNACIO Del CUeto (JIC): ¿Nos podrías hablar de tu experiencia en el campo de la intervención en el patrimonio construido tanto a escala arquitectónica como urbana?

FelIPE LeAL (FL): Muchos de mis primeros proyectos fueron de rearquitectura, es decir, intervenciones sobre edificios existentes. Cuando acometía un proyecto de remodelación o ampliación, partía de alguna preexistencia, cuyo potencial explotaba aprovechando la infraestructura: la adaptaba, la intervenía para darle un nuevo uso respetando su estructura o sus elementos destacados. Una de las primeras experiencias que tuve en este sentido fue El Hijo del Cuervo, en el Jardín Centenario de Coyoacán, una casona antigua que se adaptó como centro cultural por encargo de Alejandro Aura y Carmen Boullosa.

JIC: ¿Cuáles fueron tus primeras intervenciones en el ámbito público?

FL: Cuando fui director de la Facultad de Arquitectura de la UNAM, nuestra sede tenía muchos agregados que se le habían ido haciendo con el tiempo y que demeritaban su calidad: divisiones, canceles, muros pintados de diferentes colores, además de problemas de origen. Ante el requerimiento de nuevos espacios, acometimos varias reformas con la propuesta de "crecer hacia adentro" eliminando añadidos para recuperar su aspecto original y aprovechando los sótanos del edificio. Empezamos por quitar la pintura con la que se habían ido cubriendo los muros tras los movimientos del 68 y del autogobierno; gradualmente fuimos rescatando el color natural de la vitricota en los muros, quitamos canceles y divisiones, remodelamos las aulas y recuperamos la imagen de los talleres. Para hacer la cafetería que requería la escuela, quitamos el arriate pétreo que ocupaba la parte central del vestíbulo y en su lugar hicimos, siendo muy respetuosos de los pavimentos y la envolvente del patio, una oquedad que genera el "patio inglés" que hoy existe, un vacío que permite aprovechar el sótano para ubicar las mesas, creando un espacio de triple altura, ideal para la convivencia de alumnos y profesores.

También ampliamos la Biblioteca Lino Picaseño mediante la ubicación, en el sótano, del acervo abierto y la sala de lectura con ventanales hacia el patio de los pinos, y remodelamos el teatro Carlos Lazo. El planteamiento, también respetuoso de la envolvente general, en ningún momento transgredió el espíritu original del edificio; al contrario, resaltó, por medio de una intervención muy sutil que revaloró y realzó muchos de los elementos que le daban carácter, los valores que se habían ido perdiendo.

JIC: Una de las labores fundamentales de los servidores públicos debería ser la de impulsar la puesta en valor de nuestro patrimonio construido. En ese sentido, promoviste la idea de nominar a Ciudad Universitaria
(CU) para su inscripción en la Lista de Patrimonio Cultural de la Humanidad de la UNESCO.

FL: A partir de las intervenciones en la Facultad de Arquitectura, siendo todavía su director, empecé a ver que algunas partes del campus de $\mathrm{CU}$ eran susceptibles de mejorarse o recuperarse.

Era preocupante ver cómo, con los años, los espacios de gran riqueza plástica con que cuenta la UNAM se habían vulnerado con nuevas edificaciones o agregados que alteraban y demeritaban su valor. Haciendo una proyección, era evidente que si eso no se controlaba, en unos cuantos años el crecimiento natural de la UNAM, sumado a la inquietud de muchos directores de facultades o escuelas, que de pronto necesitaban más espacio en sus instalaciones pero no tenían conocimiento o sensibilidad arquitectónica, llevaría a desconfigurar esa maravilla que nos legaron los constructores de CU.

Se planteó que, antes de que se violentase el espíritu de su casco histórico, había que protegerlo y, sobre todo, revalorarlo, actuando no con una protección conservadora, sino con una preservación dinámica, pues no queremos que se limite su vitalidad o que no se toque para conservarlo. Tiempo atrás, varios universitarios habían impulsado una iniciativa para proponer a CU Como patrimonio de la humanidad, la cual no había fructificado por diversas razones. Entonces decidimos retomar la idea y planteársela al rector en turno, el doctor Juan Ramón de la Fuente, quien la aceptó para dar un paso adelante en la recuperación del espacio y del orgullo universitarios, éste $\tan$ golpeado tras la huelga de 1999. Fue un largo proceso que duró cerca de tres años: logramos, primero, la declaratoria de Monumento Nacional, y extendimos después todos los procedimientos hasta que finalmente, en el 2007,la Ciudad Universitaria fue declarada Patrimonio Cultural de la Humanidad.

IIC: ¿Cómo protege esta declaratoria a la Ciudad Universitaria?

FL: La protege a través de diversos mecanismos dentro de una poligonal definida que va desde el Estadio Universitario, al poniente, hasta la Facultad de Medicina, en el otro extremo, y del corredor de la Facultad de Filosofía y Letras, al norte, hasta los campos deportivos detrás del Instituto de Ingeniería, al sur; ésta es la zona a la que nos referimos cuando hablamos del "casco histórico" de CU, en la que ya no se podrá construir nada con superficie de contacto. Así se ha evitado que se lleven a cabo proyectos tan descabellados como uno que en su momento me alarmó: para solucionar el cupo de autos pretendían levantar pisos sobre algunos estacionamientos del campus, como el de Química. Y de esa circunstancia surgió otro programa importante, el del PumaBús. ${ }^{1}$

\footnotetext{
${ }^{1}$ Para conocer más detalles acerca de este sistema de transporte que
} 
JIC: El cual es otra forma de intervención: plantear estrategias o actuaciones que permitan recuperar espacio público.

FL: En este caso, el planteamiento fue no construir esos estacionamientos, sino sacar del Circuito Interior la gran cantidad de automóviles que se estacionaban sobre la vialidad y mandarlos al Estadio Olímpico de CU, preservando así el paisaje del campus.

JIC: Tras tu paso como director de la Facultad de Arquitectura, fuiste nombrado coordinador de Proyectos Especiales de la UNAM. En los años que estuviste al frente de esa coordinación se realizaron varios proyectos de intervención no sólo en $\mathrm{CU}$, sino en todos los campus que la UNAM tiene en el país. En esta labor hubo aspectos polémicos, ${ }^{2}$ como la construcción del Museo Universitario Arte Contemporáneo (MUAC), en el Centro Cultural Universitario: un edificio potente y protagónico sobre un conjunto armónico y consolidado construido 30 años antes.

FL: El terreno destinado originalmente para el MUAC estaba al oriente, en el estacionamiento que está detrás de la Sala Nezahualcóyotl, y pensamos que eso no iba a aportar nada al conjunto: había que aprovechar la oportunidad para hacerle un acceso digno al Centro Cultu-

ofrece la UNAM al interior del campus de Ciudad Universitaria, visítese PumaBús: [http://www.pumabus.unam.mx].

${ }^{2}$ Véase Vázquez Ángeles 2011: 34-37; Leal 2007: 148-156. ral Universitario, que no tenía una entrada peatonal, pues se llegaba siempre a través de los estacionamientos. La idea, entonces, fue hacer el nuevo museo en ese sitio para crear una explanada de acceso que reprodujera un poco el criterio de la explanada de Rectoría y recuperara la característica de los grandes espacios abiertos de Ciudad Universitaria.

Se planteó, pues, una plaza de acceso que vestibulara y articulara la Sala Nezahualcóyotl con el nuevo museo y los demás edificios, abriendo la perspectiva al conjunto. El arquitecto Teodoro González de León hizo un edificio que representa un nuevo ciclo de la Universidad, y creó una explanada con accesibilidad universal que, por medio de una rampa continua, te permite llegar a la Neza sin toparte con escalones ni otros obstáculos (Figura 1).

JIC: El Jefe de Gobierno del Distrito Federal, Marcelo Ebrard, creó en 2008 una nueva figura: la Autoridad del Espacio Público de la Ciudad de México. Tú fuiste el primer titular y desde ahí acometiste una serie de proyectos de recuperación de espacio público.

FL: La constante es que hemos hecho propuestas de riesgo para enaltecer el patrimonio. Desde la Autoridad del Espacio Público hemos tenido la oportunidad de Ilevar la experiencia previa de Ciudad Universitaria a otras proporciones, a la gran escala de la Ciudad de México.

La primera intervención de importancia fue la peatonalización de la calle Madero. En recorridos de análisis por

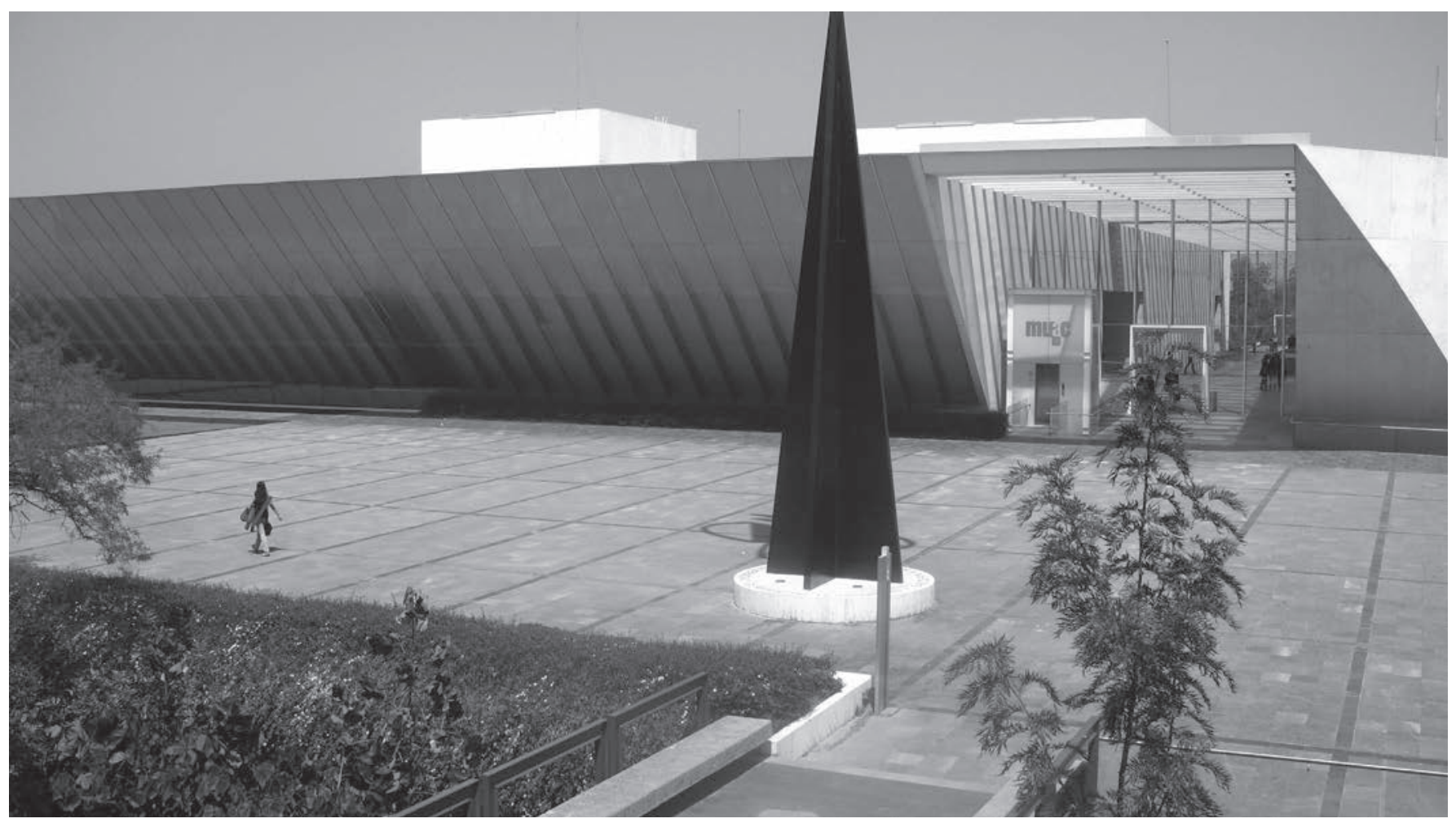

FIGURA 1. Explanada de acceso al MUAC, Centro Cultural Universitario (Fotografía Didier Gutiérrez Román, 2012; cortesía: Felipe Leal). 
esta vía emblemática del Centro Histórico constatamos que la transitaban autos con pocos pasajeros y muchos peatones que por aceras angostas y repletas de gente caminaban "rengueando", con un pie en la banqueta y otro en el arroyo, sin posibilidad de contemplar los edificios... además, nos percatamos de que ninguna construcción tenía acceso vehicular: la Casa de los Azulejos, el Palacio de Iturbide, la iglesia de la Profesa, La Esmeralda, la Torre Latino, el templo de San Francisco, el hotel Majestic. Los edificios de Madero no tienen entrada para coches... un absurdo: una calle de paso donde ninguno de los autos que entraba lo hacía para acceder a un inmueble; los automovilistas la tomaban sólo para llegar al Zócalo y dirigirse hacia el sur.

La propuesta consistió en mandar a los autos por Cinco de Mayo, que es más ancha, cambiarle el sentido para que entren desde el Eje Central hacia el Zócalo y tengan como remate visual las torres de Catedral, y así poder hacer peatonal la calle Madero (Figura 2).

JIC: Pero no todos pensaban igual, hubo muchas opiniones en contra...

FL: En un principio, todos los comerciantes y los ingenieros de tránsito estuvieron en desacuerdo. Propusimos poner el ejemplo y fuimos cerrando gradualmente la caIle: primero un lunes, a la semana siguiente un martes, a la otra un miércoles, siempre con la advertencia de los opositores: "bueno, les fue bien porque era lunes, o martes, ya verán cuando llegue el viernes, va a ser un desastre"; hasta que llegó el domingo y demostramos que no pasaba nada. Los comerciantes en contra decían que ni hablar, que iban a vender menos; finalmente los convencimos y la peatonalización de Madero se logró. Actualmente transitan por esta calle 120000 personas diarias, 200000 en fines de semana, los comerciantes venden el doble, las rentas han aumentado, las actividades se han multiplicado: el área está viva durante la noche porque está muy bien iluminada y además te permite caminar con parsimonia, disfrutar la riqueza de los edificios, que son magníficos: uno art déco, uno funcionalista, otros barrocos o eclécticos. La gente camina zigzagueando, se detiene en las bancas-escultura de bloques de mármol que hizo Jorge Yázpik; se introdujo vegetación para hacerla más amable y se hizo un "lomo" sobrepuesto al arroyo para borrar la división entre calle y banqueta con un pavimento nuevo de color claro — que también fue muy criticado- que resaltara la intervención nueva.

JIC: El proyecto en la Plaza de la República y el Monumento a la Revolución fue objetado por personajes destacados e influyentes en el ámbito de la conservación, ${ }^{3}$

\footnotetext{
${ }^{3}$ Véase Flores Marini (2011: 258-260) y notas periodísticas sobre la oposición al proyecto en La Jornada, "Cultura" (García Hernández 2010), El Universal (Sierra 2010 y Robles 2010) y El Informador (El
}

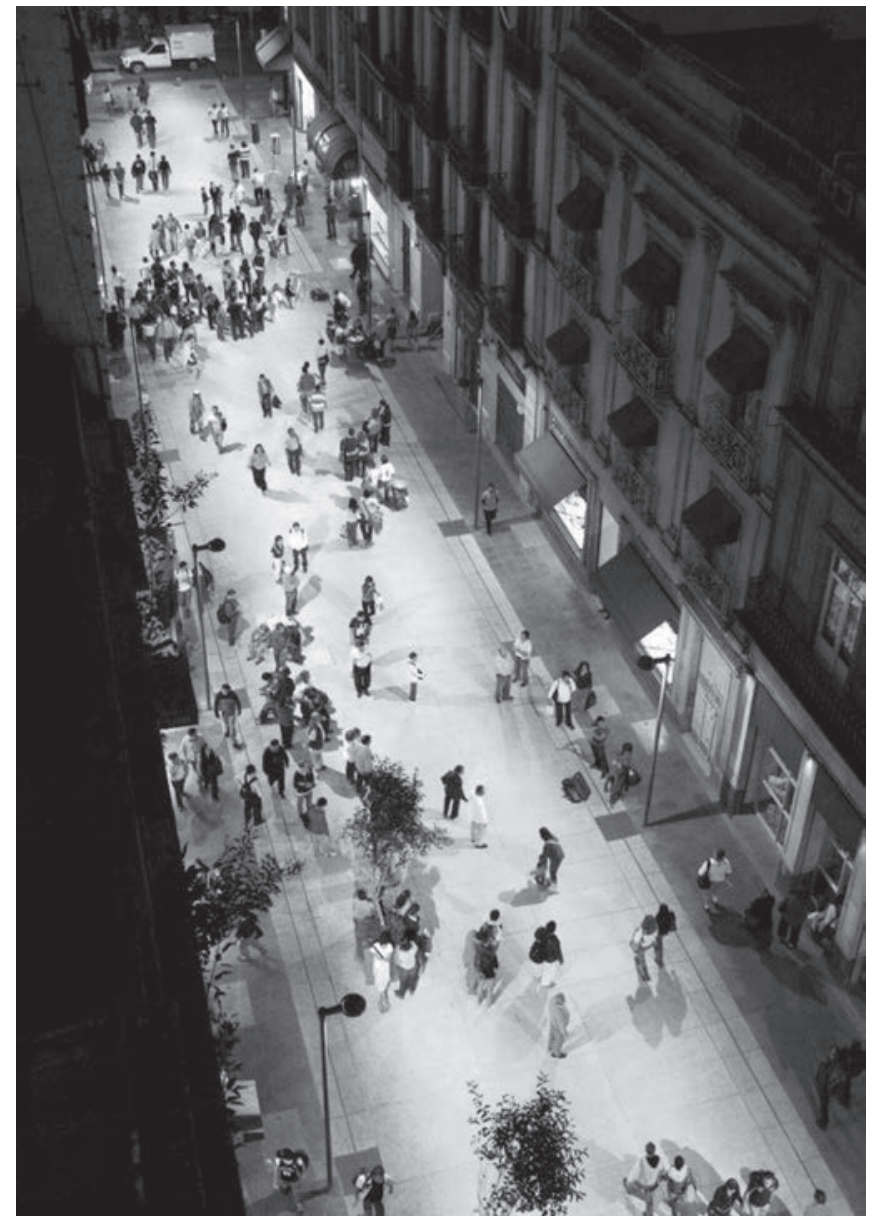

FIGURA 2. Vista panorámica de la calle Madero, Centro Histórico de la Ciudad de México (Fotografía Jean Sidaner, 2010; cortesía: Felipe Leal).

sobre todo por el nuevo elevador que, desde su punto de vista, "violentaba" el espacio arquitectónico.

FL: No hay que centrar el punto en un objeto; se trata de una regeneración urbana mucho mayor, en la que se rescataron $65000 \mathrm{~m}^{2}$ para el peatón. La intervención va desde Reforma hasta Insurgentes, todo lo que es la avenida de la República, que estaba abandonada; se reordenaron las asta banderas de todos los estados del país, se plantaron las palmas que faltaban, se quitaron carriles a los vehículos con el fin de ganar espacio para el peatón, se remozó la Plaza de la República en su totalidad. Ésta era un estacionamiento abandonado, una plaza donde se hacinaban los autos, con una utilización sobre $30 \%$ del suelo urbano; todos los demás edificios, en desuso (algunos por conflictos laborales, como el Frontón México), lotes baldíos, había unos baños públicos, y el monumento no se visitaba. Los recintos funerarios de los héroes de la Revolución, salvo el de Lázaro Cárdenas, estaban abandonados, Ilenos de humedades, sin iluminación.

Informador 2010). A favor véase Krieger (2011: 267-274). 


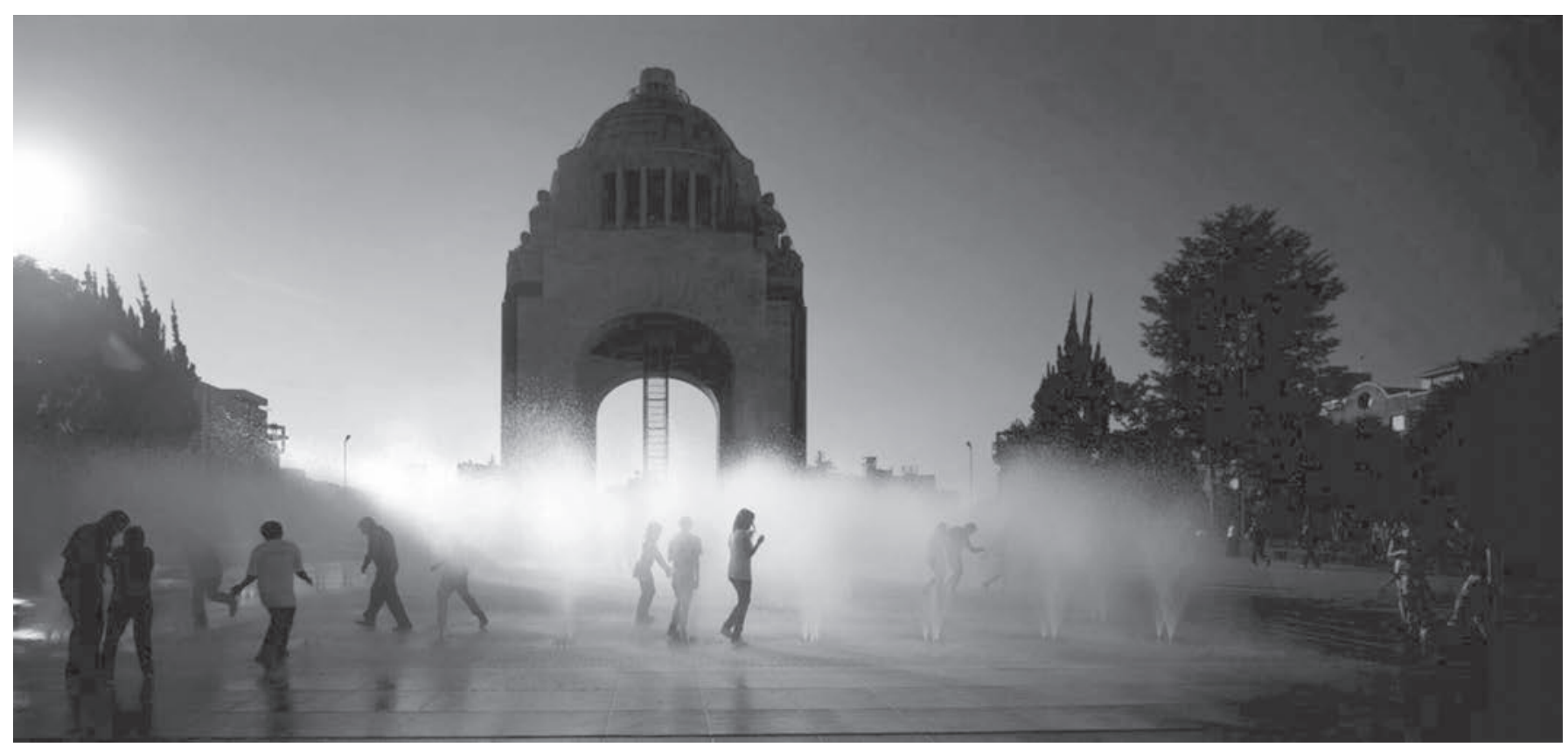

FIGURA 3. Plaza de la República y Monumento a la Revolución (Fotografía Fernando Cordero, 2011; cortesía: Felipe Leal).

Entonces se hizo una intervención urbana mayor, que rescata todo el entorno mejorando las calles circundantes, uniendo desde avenida Insurgentes, a la altura de la colonia Tabacalera, hasta el edificio de la Lotería Nacional, en Paseo de la Reforma, cerca de $1 \mathrm{~km}$ para caminar, todo regenerado. Y además se restauró el monumento, que ninguno de nosotros había visto limpio: siempre deteriorado, con la cúpula sucia, y en cuyo sótano estaba el Museo Nacional de la Revolución, con una buena colección pero con espacios inadecuados y una museografía muy precaria. Se recuperó la cimentación de acero de lo que iba a ser el Palacio Legislativo, y se aprovechó el espacio que forman sus grandes cartelas metálicas para reubicar el museo con una nueva propuesta museográfica. La parte más rica del monumento art déco no es su exterior, sino su interior, que es extraordinario, toda una lección de arquitectura y de geometría, con la doble cúpula y su mirador, desde el que Juan $\mathrm{O}^{\prime}$ Gorman pintó su famosa vista aérea de la ciudad de México. Optamos por restaurar ortodoxamente el edificio y colocar un nuevo elevador para llegar a ese mirador (Figura 3).

JIC: El famoso elevador, la manzana de la discordia...

FL: Otra intervención de riesgo, pero que teníamos clarísima: no era suficiente actuar sobre el monumento: ¿de qué nos iba a servir restaurarlo si no se visitaba? Era necesario que la plaza tuviera otros atractivos. Pusimos unas fuentes para el disfrute del público—el agua es un magneto, los jóvenes juegan y se mojan en ellas, pues son interactivas-, dando vida a la plaza y Ilenándola de alegría. Además, nos pareció fundamental iluminar el edificio por la noche para que reluciera su esplendor $y$, sobre todo, que se pudiera subir de nuevo al mirador. Ya no lo podíamos hacer por el viejo y pequeño elevador que estuvo en la "pierna", donde están ahora los restos de Lázaro Cárdenas, por lo que pensamos en uno nuevo, panorámico, que ascendiera por la parte central. Al principio la propuesta causó mucha polémica, pero demostramos que era la forma más sensata de permitir al público disfrutar de esas vistas con un elemento atractivo que no afecta la estructura del edificio y que, en un momento dado, puede removerse. Los detractores decían que "los monumentos no se visitan", pero existen muchos ejemplos que prueban lo contrario: la Torre Eiffel y el Arco del Triunfo se visitan en París; el Monumento a Vittorio Emanuele II, en los foros romanos, a través de un nuevo elevador. También se visita la Mole Antonelliana, el edificio más emblemático de Turín, y se sube a su mirador por un elevador.

JIC: Todos son ejemplos de intervenciones de riesgo...

FL: El patrimonio hay que conservarlo pero hay que vivirlo, y lo mejor es hacer una preservación dinámica con toques de actualidad. Con las adecuaciones que hicimos en su momento, la Facultad de Arquitectura realzó su esplendor de los años cincuenta y le dimos nueva vida para arrancar el siglo XXI.

Después hemos seguido haciendo propuestas de riesgo para enaltecer el patrimonio, como las de CU: no era fácil sacar a los vehículos que durante años habían estacionado sobre el Circuito Interior afectando el paisaje del campus, bloqueando las perspectivas, haciendo intransitable esa vialidad y deteriorando el patrimonio, por lo que se decidió tomar una medida de riesgo con el pro- 


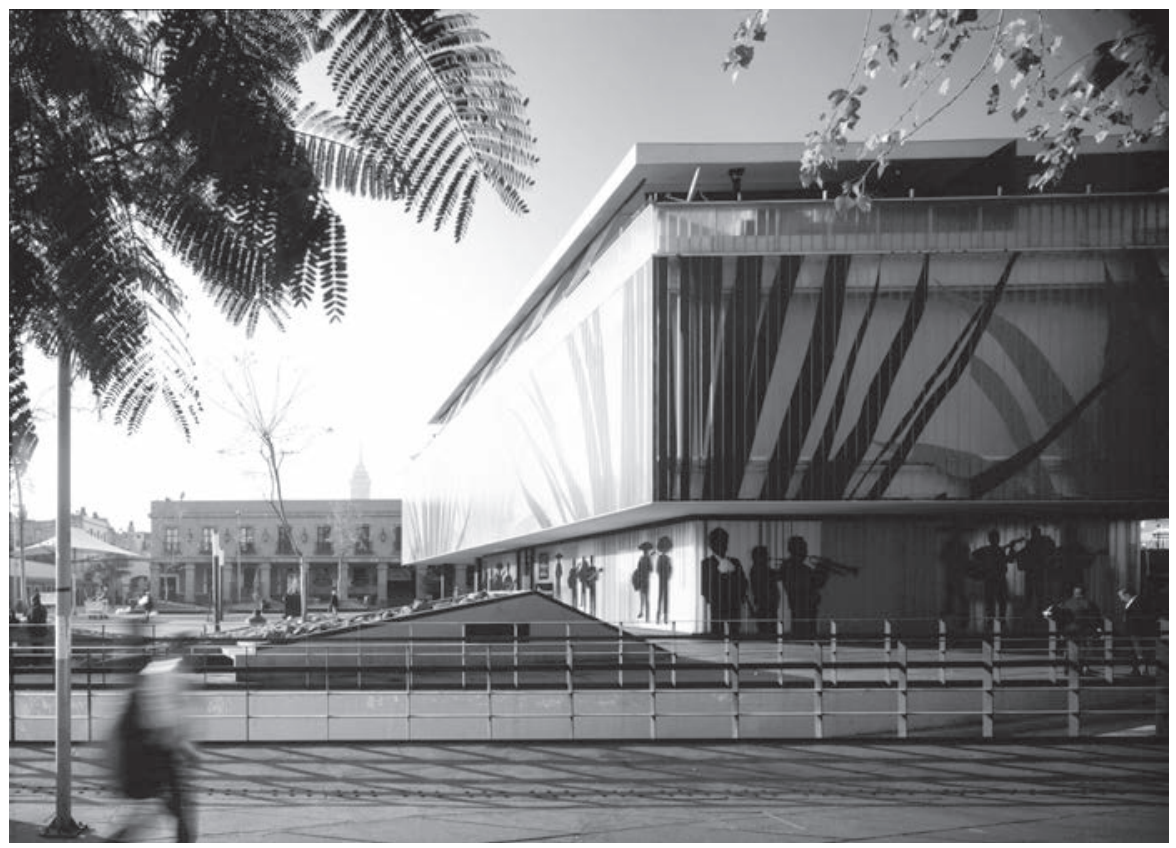

FIGURA 4. Museo del Tequila y el Mezcal en la Plaza Garibaldi (Fotografía Fernando Cordero, 2011; cortesía: Felipe Leal).

yecto del PumaBús. De riesgo fue también proponer a CU como patrimonio de la humanidad, pues había quienes opinaban que esa idea de preservación atentaba contra el futuro de la institución, que la iba a limitar. Y volvimos a pisar terrenos pantanosos — en un área fuera de la Declaratoria - con la intervención del MUAC, que le dio otro perfil al Centro Cultural Universitario, lo reanimó, abrió un ciclo nuevo con un edificio nuevo y una nueva actividad en el conjunto: las artes visuales. Éstas fueron algunas de las acciones más fuertes que se hicieron en $\mathrm{CU}$, todas ellas intervenciones de riesgo.

Y, ya como Autoridad del Espacio Público, acometimos la peatonalización de Madero, que se revitalizó, y hoy nos complacemos con la vista desde el presente de sus magníficos edificios del pasado. Intervenimos, asimismo, la Plaza de Garibaldi, otra zona emblemática de la ciudad que estaba muy abandonada, donde el planteamiento fue darle una nueva vida de día y quitarle el estigma de lugar nocturno e inseguro a través del remozamiento de la plaza, la inserción de juegos infantiles y vegetación, y la sustitución del falso pórtico-parián de los años ochenta con el nuevo edificio-lámpara que aloja al Museo del Tequila y el Mezcal, y que aporta a la plaza la luminosidad de algo contemporáneo (Figura 4).

En el caso del Monumento a la Revolución, además de hacer una cuidadosa intervención de restauración del objeto arquitectónico, revitalizamos la Plaza de la República con un pavimento claro, vivo y alegre que sustituye a aquel oscuro, sucio y triste que tenía, y hoy vemos las carriolas, las bicicletas, las sillas de ruedas; a las mamás, los niños, los ancianos, los turistas, personas de diversos sectores sociales que disfrutan el espacio, lo que demuestra que lo más importante del patrimonio es que tenga vida. Y en este último caso, si no hubiera fuentes y elevador, no tendríamos la afluencia de público que hoy goza la plaza. Era un espacio que repelía a la gente y ahora es un polo de atracción.

JIC: Después de tu gestión como Autoridad del Espacio Público fuiste nombrado secretario de DesarroIlo Urbano y Vivienda del GDF. ¿Esta nueva actividad te permite seguir haciendo propuestas de recuperación y revitalización de espacios degradados o semiperdidos?

FL: Esta figura de "Autoridad..." se creó con la preocupación de solucionar el deterioro del espacio público en la ciudad, tan abandonado durante años. Con las acciones que emprendimos se ha empezado a abatir el rezago histórico que sufre la calidad de las áreas comunes en la capital, pero hay que seguir trabajando, ahora desde la Seduvi. La gente se queja: "Está muy bien lo que hicieron en Madero o en la Plaza de la República, pero ¿cuándo van a llegar a Iztapalapa o Milpa Alta?", y tiene toda la razón: ahora es necesario darle continuidad a la labor; estas políticas deben mantenerse sin que importe quién sea jefe de Gobierno.

JIC: En este sentido es muy interesante la intervención que acaban de hacer a la Alameda de Santa María la Ribera...

FL: Allí se recuperó el quiosco morisco restaurando su estructura metálica, todas sus piezas prefabricadas, sus colores y sus vitrales. Y se remozó la plaza cambiando pavimentos, eliminando los escalones y desniveles que tenía, recuperando sus fuentes y su vegetación. Se rescató así el centro de un barrio emblemático de la capital, el quiosco y la alameda, que son parte de la identidad de esa colonia (Figura 5).

JIC: Nos has hablado de diversas intervenciones arquitectónicas y urbanas, en algunos casos muy potentes. ¿Has tenido algún tipo de influencia o de inspiración a la hora de emprenderlas?

FL: Siempre hay una referencia. Por fortuna he visitado muchas partes del mundo, y en cada lugar observo y me quedo con ideas que después asocio con proyectos que se están trabajando o que van surgiendo. El caso de la peatonalización de Madero tiene muchos referentes, sobre todo en Europa: me impresionó mucho la Vía Garibaldi, también en Turín, y tantas otras calles en centros 


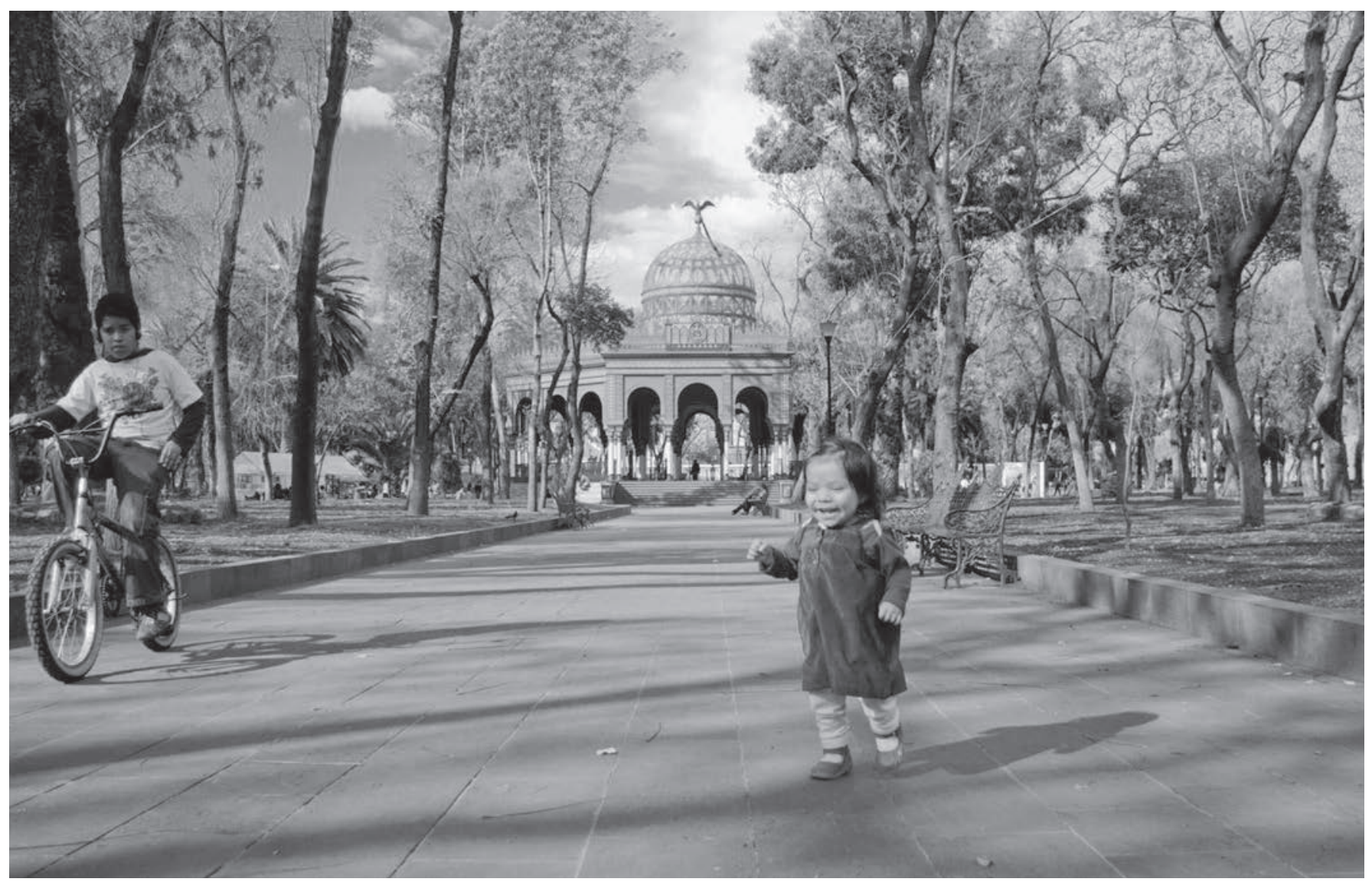

FIGURA 5. Alameda de Santa María la Ribera (Fotografía David Osnaya, 2011; cortesía: Felipe Leal).

históricos de ciudades europeas. París y Barcelona dieron en su momento un brinco cualitativo con sus intervenciones de revitalización urbana. Más recientemente -y más vinculados con nuestro contexto-, están los ejemplos de Bogotá y Medellín; los colombianos han hecho muy bien las cosas. O el caso de Nueva York, todo lo que se ha realizado para los peatones, las intervenciones en Broadway y Chelsea... Al visitar y analizar otras ciudades te quedas con lo que consideras más viable y con lo que podrías aplicar en tu contexto. Cuando visité la Mole Antonelliana en Turín, con su elevador que desemboca en la linternilla de su impresionante cúpula, el proyecto del Monumento a la Revolución ya estaba en ciernes y pensé: "por ahí puede ser".

JIC: A mi parecer, a lo largo de esta charla ha quedado patente la importancia de las intervenciones que has ido haciendo a lo largo de tu vida profesional, ya sea en el ámbito privado o desde los puestos públicos que has tenido, ya que han logrado frenar la degradación y reactivar la vida de parte de nuestro patrimonio arquitectónico y urbano.

FL: La finalidad de estas intervenciones es, en efecto, frenar la degradación y el olvido antes de que desaparezca un bien patrimonial, y posteriormente reanimarlo, ponerlo en escena. Me acuerdo mucho de aquella campaña de "Barcelona, ponte guapa": hay que poner de nuevo guapa a esa mujer que se había abandonado, y reavivarla. El mejor indicador de todo esto es el uso. El patrimonio es para vivirlo hoy; la peor manera de conservar el patrimonio construido es la preservación museística anacrónica. El uso es el mejor de los cuidados.

JIC: El uso es la manera en que uno se encariña con el sitio, lo hace suyo, lo defiende y lo cuida.

FL: ¡Y se lo apropia! Todos los edificios patrimoniales se han reciclado porque la sociedad cambia, la vida cambia. No podemos congelar el patrimonio en sus orígenes, debe irse adaptando a las condiciones de su momento porque, si no lo hace, muere. La Ciudad de México debe recuperar su autoestima; es una ciudad extraordinaria que tiene muchos problemas pero también grandes cosas positivas. Hoy muchos chilangos, habitantes de la capital del país, están orgullosos de ella porque pueden tomar una bicicleta, porque disfrutan de una plaza bella, porque los domingos pueden salir y ser dueños del Paseo de la Reforma, que está consolidándose con nuevas construcciones, porque pueden caminar por Madero. Todo eso es 
motivo de orgullo y de autoestima, y eso sólo se consigue poniendo el patrimonio del pasado en el presente para disfrute de las generaciones de hoy.

El uso es lo más importante y se trata de que las ciudades vivan, que las construcciones se renueven, y si al patrimonio se le da un uso actual y atractivo, vivirá por siempre. $Y$ este patrimonio puede ir desde la pequeña casona abandonada que se recuperó para El Hijo del Cuervo, hasta los $65000 \mathrm{~m}^{2}$ que se regeneraron en la Plaza de la República; o pueden disfrutar de él los 400 parroquianos que se reúnen en el inmueble de Coyoacán, o los miles de peatones que caminan por Madero. Y la mejor valoración es la respuesta del público que usa y vive ese patrimonio.

Al término de la entrevista, mientras veía alejarse la figura menuda, enérgica y siempre apurada de Felipe Leal, pensé en su capacidad de trabajo, que no ha dejado de sorprenderme en los 20 años que han pasado desde que nos reunió la vida académica en la Facultad de Arquitectura de la UNAM, cuando él coordinaba el Taller Max Cetto y yo me incorporaba como profesor: es un arquitecto de probada capacidad proyectual, que despliega una actividad casi frenética, contagiosa, que genera a su alrededor una sinergia particular; posee una gran capacidad de organización que le sirve para guiar a quienes forman parte de su equipo interdisciplinario con ideas claras y contundentes, muchas veces arriesgadas o difíciles de digerir. Cuando alguien propone e impulsa tantos proyectos de diversa índole, en muchos casos tan polémicos y criticados - pero también tan valientes y trascendentes- como los que se han comentado aquí, queda inevitablemente expuesto a todo tipo de crítica. En mi opinión, su labor está dejando una Ciudad de México diferente para el futuro, una ciudad más amable y habitable. La distancia en el tiempo permitirá evaluar sus intervenciones más controvertidas, aquellas que han conllevado el mayor riesgo en su planteamiento y ejecución.

\section{Referencias}

Flores Marini, Carlos

2011 Conservación del patrimonio monumental. Una biografía arquitectónica, México, Amaltea Editores.
García Hernández, Arturo

2010 "Solicitan a Ebrard y Lujambio no instalar elevador en el Monumento a la Revolución", La Jornada, "Cultura", 21 de agosto, documento electrónico disponible en [http:// www.jornada.unam.mx/2010/08/21/cultura/a07n1 cul], consultado en febrero del 2012.

El Informador

2010 "ICOMOS-México señala irregularidades en Monumento a la Revolución", El Informador, 9 de agosto, documento electrónico disponible en [http://www.informador.com.mx/ cultura/2010/224406/6/icomos-mexico-senala-irregularidades-en-monumento-a-la-revolucion.htm], consultado en febrero del 2012.

Krieger, Peter

2011 "La revitalización necesaria del Monumento a la Revolución", Anales del Instituto de Investigaciones Estéticas, UNAM, 98, 267-274, documento electrónico disponible en [http:// www.analesiie.unam.mx/pdf/98_267-274.pdf], consultado en febrero del 2012.

Leal Fernández, Felipe (coord. general) et al. 2007 Patrimonio renovado UNAM, México, UNAM.

Mérigo, Gabriel, Enrique Lastra y Nicola Lorusso

2011 Restauración y rehabilitación de la Plaza de la República y Monumento a la Revolución, México, Autoridad del Espacio Público-GDF.

Robles, Johana

2010 "GDF apostó a obra que 'dejará huella'", El Universal, "Ciudad", 20 de noviembre, documento electrónico disponible en [http://www.eluniversal.com.mx/ciudad/104158.html], consultado en febrero de 2012.

Sierra, Sonia

2010 "Se mantendrá elevador en el Monumento: GDF", El Universal, "Cultura", 21 de agosto, documento electrónico disponible en [http://www.eluniversal.com.mx/cultura/63664. html], consultado en febrero del 2012.

Vázquez Ángeles, Jorge

2011 "Retrato de museo con olor a restorán", Casa del Tiempo, 40, 34-37, documento electrónico disponible en [http:// www.uam.mx/difusion/casadeltiempo/40_iv_feb_2011/ casa_del_tiempo_elV_num40_34_37.pdf], consultado en febrero del 2012. 


\section{Resumen}

En esta contribución, Felipe Leal dialoga con Juan Ignacio del Cueto acerca de las intervenciones arquitectónicas que ha realizado a diferentes escalas en torno del patrimonio construido en la Ciudad de México a lo largo de su carrera como profesional independiente y como servidor público. De acuerdo con Leal, una constante en sus propuestas ha sido la de caracterizarse por ser de riesgo, es decir, intervenciones que, a través de un uso actual y atractivo, buscan revitalizar el patrimonio del pasado para disfrute de las generaciones de hoy. Algunos ejemplos emblemáticos que comenta en esta entrevista son las adecuaciones hechas en la Facultad de Arquitectura de la UNAM (1997-2005), la construcción del MUAC en el Centro Cultural Universitario, la peatonalización de la calle Madero en el Centro Histórico y la rehabilitación de la Plaza de la República con el Monumento a la Revolución, entre otros.

\section{Palabras clave}

Arquitectura, intervención, revitalización urbana, patrimonio construido.

\section{Abstract}

In this article, Felipe Leal talks to Juan Ignacio del Cueto about the architectural interventions that the former has made on different scales to built heritage in Mexico City throughout his career as a freelance professional and as a public servant. According to Leal, a constant in his work has been to develop so-called risky interventions: projects that seek to revitalize past heritage by giving it a modern and attractive use so that it might be enjoyed by today's generations. Some of the emblematic examples mentioned in this interview are the adaptations made to UNAM's Architecture faculty buildings (1997-2005), the construction of the MUAC at the Centro Cultural Universitario, to pedestrianize Madero Street in Mexico City's historic downtown district and the renovation of the Plaza de la República and the Monumento a la Revolución.

\section{Keywords}

Architecture, architectural intervention, urban regeneration, built heritage.

Título en inglés: "Risky intervention, a way to revitalize built heritage. Interview with Felipe Leal" 